\title{
Computational simulation of motion of a rescue module during its launching from ship at rough sea
}

Czesław Dymarski, Prof.

Paweł Dymarski, Ph.D.

Gdańsk University of Technology, Polnad

\begin{abstract}
This paper is a continuation of the work titled: "A computational model for simulation of motion of rescue module during its launching from stern ramp of a ship at rough sea". It presents results of computer simulations of motion of a rescue module with embarked persons during its launching on rollers along stern ramp of a ship at rough sea. The simulations were conducted for a selected ship fitted with a launching ramp, for a few selected scenarios of sea conditions. It was assumed that during this operation the ship drifts across direction of wave propagation.
\end{abstract}

Keywords: lifeboat; rescue boat launch; innovation; launch ramp aft; computational model for simulation lifeboat; rescue boat launch; innovation; launch ramp aft; computational model for simulation

\section{INTRODUCTION}

This paper is a continuation of the work titled: "A computational model for simulation of motion of rescue module during its launching from stern ramp of a ship at rough sea" [1]. A computer software based on the model was used for calculation of dynamic runs of position of contours of the ramp and rescue module moving along it as well as motion parameters of centre of gravity of the module during its launching from a ship at rough sea. This work was conducted within the frame of the European project SAFECRAFTS (Safe Abandoning of Ships - improvement of current Life Saving Appliances Systems), task: Establish escape craft dynamics, craft detached - novel systems.

\section{DATA FOR COMPUTATIONS}

The calculations were conducted for a ship of the length $\mathrm{L}=265 \mathrm{~m}$, breadth $\mathrm{B}=32 \mathrm{~m}$ and draught $\mathrm{T}=7,8 \mathrm{~m}$, which drifts across direction of wave propagation. Fig. 1 shows, in a simplified way, contour of a stern ramp fitted with a floating pontoon, and contour of a rescue module with water surface marked on it. The elevation of the ramp fixing axle over water level , $\mathrm{H}_{\mathrm{RF}}$, and the ramp slope angle $\mathrm{a}_{\mathrm{R}}$ are also shown there.

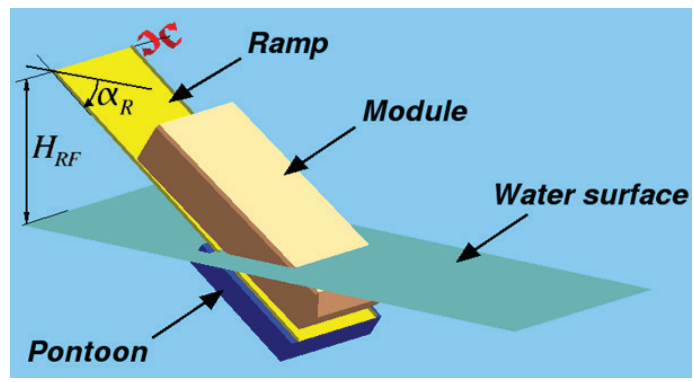

Fig. 1. The system consisted of a ramp, module, pontoon and water
Pontoon:

$\begin{array}{lccc}\text { Length } & L & \mathrm{~m} & 6.70 \\ \text { Breadth } & B & \mathrm{~m} & 6.50 \\ \text { Depth } & H & \mathrm{~m} & 1.20 \\ \text { Total volume } & V & \mathrm{~m}^{3} & 52.26 \\ \text { Mass } & M_{P} & \mathrm{~kg} & 8000 \\ \text { Moment of inertia around } x_{0} \text {-axis } & I_{x x 0} & \mathrm{~kg} & 29000 \\ \text { Moment of inertia around } y_{0} \text {-axis } & I_{y y 0} & \mathrm{~kg} & 31000 \\ \text { Moment of inertia around } z_{0} \text {-axis } & I_{z z 0} & \mathrm{~kg} & 58000\end{array}$

It was assumed that the pontoon centre of mass lies in its centre of geometry.

Moments of inertia Ixx0, Iyy0 and Izz0 were calculated with the use of the following formulas:

$$
\begin{aligned}
& I_{x x 0}=\frac{1}{12} M_{P}\left(B^{2}+H^{2}\right) \\
& I_{y y_{0}}=\frac{1}{12} M_{P}\left(L^{2}+H^{2}\right) \\
& I_{z z 0}=\frac{1}{12} M_{P}\left(L^{2}+B^{2}\right)
\end{aligned}
$$

Ramp (without pontoon):

$\begin{array}{llll}\text { Length } & L & \mathrm{~m} & 18.30 \\ \text { Breadth } & B & \mathrm{~m} & 5.80 \\ \text { Mass } & M_{R} & \mathrm{~kg} & 22000 \\ \text { Moment of inertia around } x_{0} \text {-axis } & I_{x x 0} & \mathrm{~kg} & 62000 \\ \text { Moment of inertia around } y_{0} \text {-axis } & I_{y y 0} & \mathrm{~kg} & 614000 \\ \text { Moment of inertia around } z_{0} \text {-axis } & I_{z z 0} & \mathrm{~kg} & 676000 \\ \text { Maximum slope angle (in relation to } & & \mathrm{deg} & 36\end{array}$


Module:

$\begin{array}{lccc}\text { Length } & L & \mathrm{~m} & 6.30 \\ \text { Breadth } & B & \mathrm{~m} & 5.65 \\ \text { Depth } & H & \mathrm{~m} & 2.50 \\ \text { Draught } & T & \mathrm{~m} & 0.60 \\ \text { Mass } & M_{M} & \mathrm{~kg} & 43626 \\ \text { Longitudinal coordinate of mass centre } & x_{G 0} & \mathrm{~m} & 6.30 \\ \text { Vertical coordinate of mass centre } & z_{G 0} & \mathrm{~m} & 1.09 \\ \text { Moment of inertia around } x_{0} \text {-axis } & I_{x x 0} & \mathrm{~kg} & 125000 \\ \text { Moment of inertia around } y_{0} \text {-axis } & I_{y y 0} & \mathrm{~kg} & 334000 \\ \text { Moment of inertia around } z_{0} \text {-axis } & I_{z z 0} & \mathrm{~kg} & 334000\end{array}$

where $I_{x x 0}, I_{y y 0}, I_{z z 0}$ was calculated by using the following formulas [7]:

$$
\begin{gathered}
I_{x x 0}=(0.3 B)^{2} M_{M} \\
I_{y y_{0}}=I_{z z 0}=(0.225 L)^{2} M_{M}
\end{gathered}
$$

\section{RESULTS OF COMPUTATIONS}

\section{Scenario No. 1}

The first set of calculation results graphically presented in Fig. 2, 3a and 3b, concerns favourable, but characteristic condition : calm sea, ship a little trimmed by head so as to get maximum value of slope angle of the ramp. It means that the ramp rests on ship hull structure and the rescue module, when moving along the ramp, would not cause any change in its slope angle.

$\begin{array}{llll}\begin{array}{l}\text { Elevation of ramp fixing } \\ \text { axle }\end{array} & H_{R F} & m & 9.0 \\ \text { Ramp slope angle at } \mathrm{t}=0 & \alpha_{R} & \mathrm{deg} & 36.0 \\ \text { Wave height } & H_{W} & m & 0.0 \\ \text { Wave period } & T_{W} & s & - \\ \text { Wave phase shift } & t_{0 \mathrm{~W}} & s & -\end{array}$

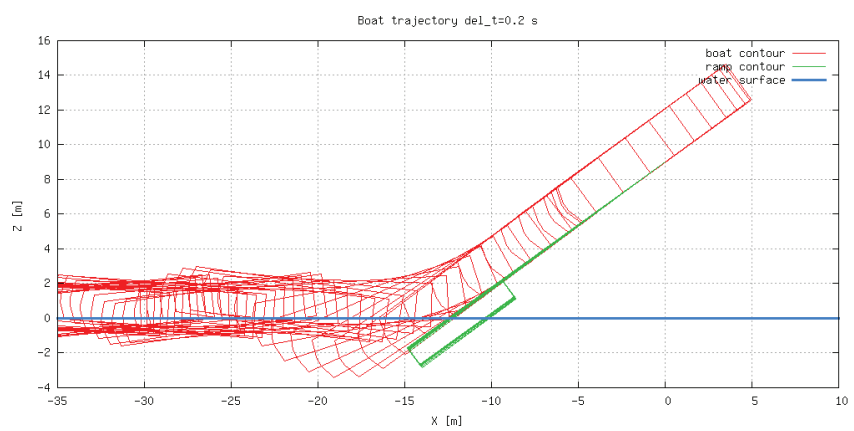

Fig. 2. Module and ramp contours in function of time,
A uniformly accelerated motion of the module along an emerging part of the practically motionless ramp may be clearly observed in the figure. The ramp slope angle, only a little increasing during the rolling down of the module, results from the fact that no flexibility of the ramp supports has been taken into account in the computational model. Maximum value of immersion of the fore part of the module is not very large in this case as it amounts to about 3,5 m only, and lasts for a short time. After that, motion of the module stabilizes very fast.

More information on the motion of the rescue module may be achieved from examining Fig. $3 \mathrm{a}$ and $3 \mathrm{~b}$ which present runs of changes in acceleration and velocity of the module centre of gravity. Three characteristic phases of the motion may be distinguished, namely:

- 1st phase : the free rolling down of the module along the almost motionless ramp, during the period from the beginning of the motion up to the instance when the face side of the module reaches contact with water. Almost constant values of acceleration and angular velocity as well as constant rate of horizontal and vertical components of velocity of the module are characteristic for this phase of the motion.

- 2nd phase : the going into water of the module being still in contact with the ramp. This phase begins with a sudden change in sign of values of linear acceleration and velocity, at insignificant changes in values of angular acceleration and velocity, as a result of a high resistance to motion of the module in water, leading to its full braking at last.

The phase is ended with a noticeable disturbance of runs , especially of accelerations in the instance of loss of contact between the module and ramp.

- 3rd phase : The free going of the module off the ramp. In this phase changes in values of all motion parameters are distinctly lower and lower, that means the motion stabilizes as a result of damping action of water.

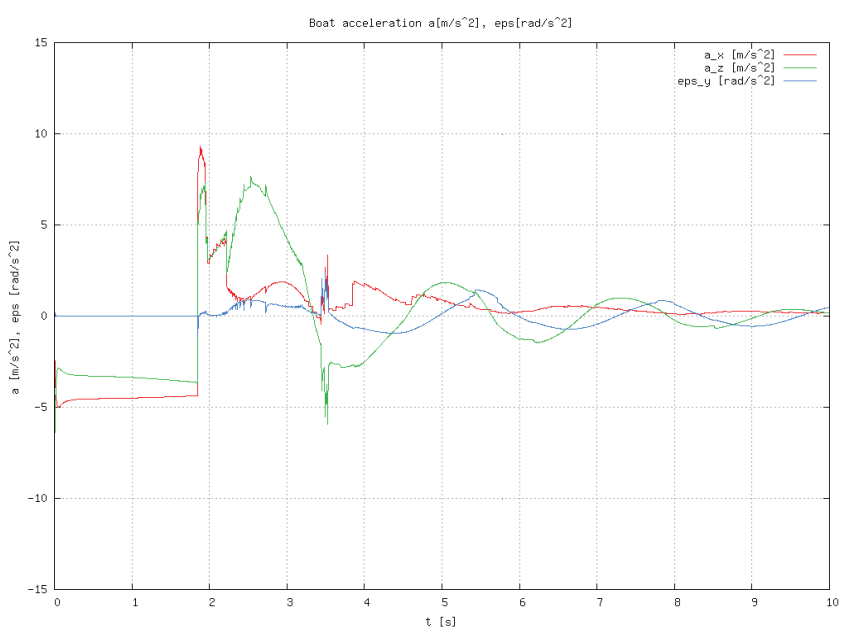

Fig. 3a. Module acceleration components: horizontal $\alpha_{x}$, vertical $\alpha_{z}$ and angular $\varepsilon_{\mathrm{z}}$ 


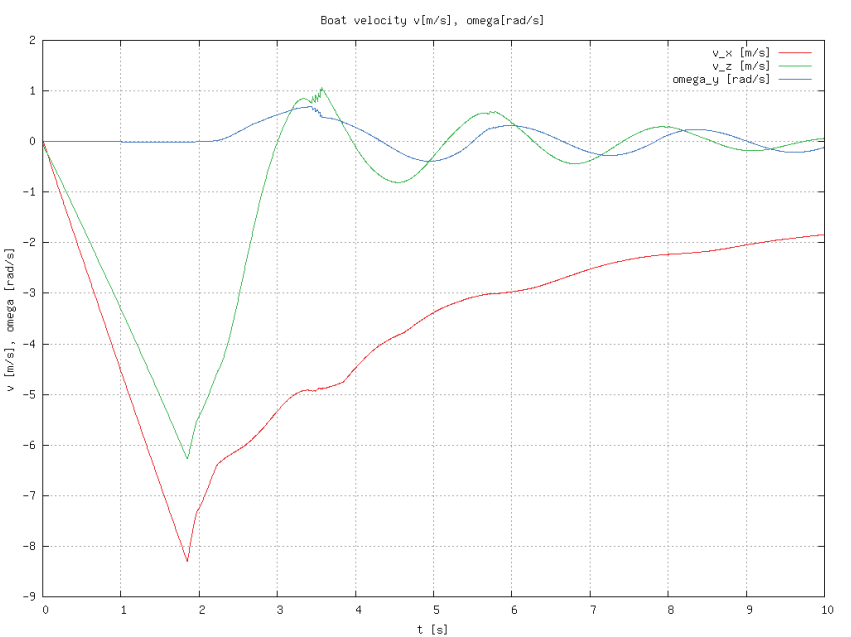

Fig. 3b. Module velocity components : horizontal $v_{x}$, vertical $v_{z}$ and angular $\omega_{y}$

Scenario No. 2

This scenario concerns the conditions which are close to normal, i.e.: rough sea, ship without trim, the elevation $\mathrm{H}_{\mathrm{RF}}$ - lower than in the previous case; owing to this, the slope angle of the ramp is smaller than maximum one, that makes its changing during launching the module, possible. The conditions allow to better assess influence of application of the ramp - pontoon system and wave action on rescue module dynamics.

$\begin{array}{llll}\text { Ramp fixing axle elevation } & H_{R F} & m & 7.0 \\ \text { Ramp slope angle at } \mathrm{t}=0 & \alpha_{R} & d e g & 26.0 \\ \text { Wave height } & H_{W} & m & 5.0 \\ \text { Wave period } & T_{W} & s & 12.0 \\ \text { Wave phase shift } & t_{0 \mathrm{~W}} & s & 0.0\end{array}$

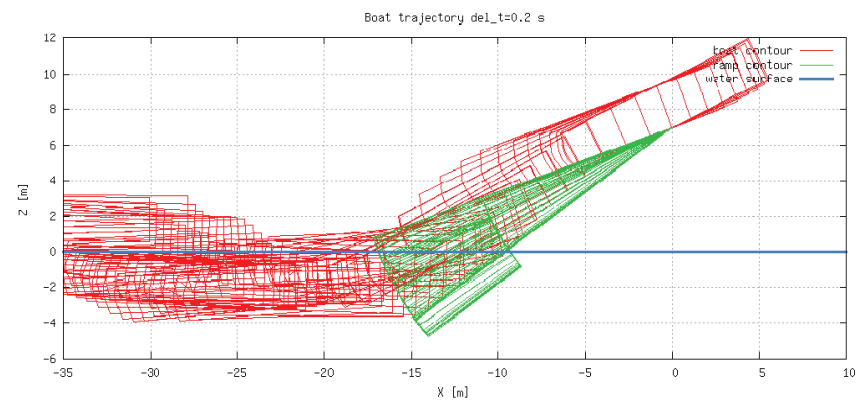

Fig. 4. Module and ramp contours in function of time, $\Delta t=0.2 \mathrm{~s}$
As results from Fig. 4 and 5, the runs of contours of the ramp and module and values of motion parameters of module gravity centre during launching show much greater dynamic features in comparison to the first scenario. The maximum draught of the ramp reached almost $5 \mathrm{~m}$. Similarly, the maximum draught of the module increased up to $4 \mathrm{~m}$, and amplitude of its vertical displacements was also greater. Values of acceleration and velocity of motion of the module are changeable in all launching phases, though the acceleration and velocity damping process is close to that calculated for the previous case. The characteristic change in sign of the vertical velocity component in the final phase of motion of the module results from its heave on wave crest.

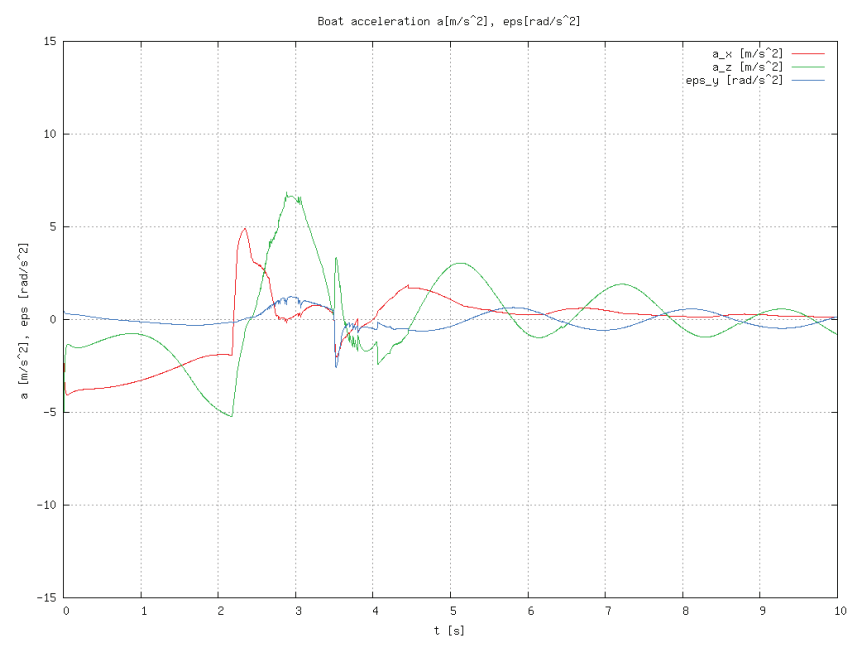

Fig. 5a. Module acceleration components: horizontal $\alpha_{x}$, vertical $\alpha_{z}$ and angular $\varepsilon_{\mathrm{z}}$

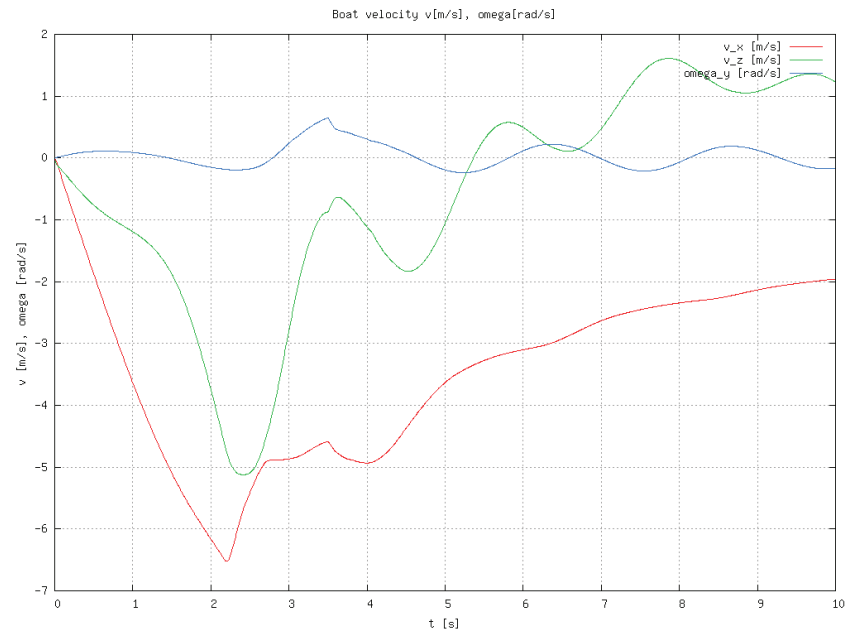

Fig. 5b. Module velocity components : horizontal $v_{x}$, vertical $v_{z}$ and angular $\omega_{\mathrm{y}}$

Scenario No. 3

The research results presented below, were calculated for similar sea conditions as used in the previous case, but for the start of launching in the instance when the wave undergoes shift by a half of its length, in contrast to the previous case. It enables to assess influence of this parameter on module motion dynamics. 


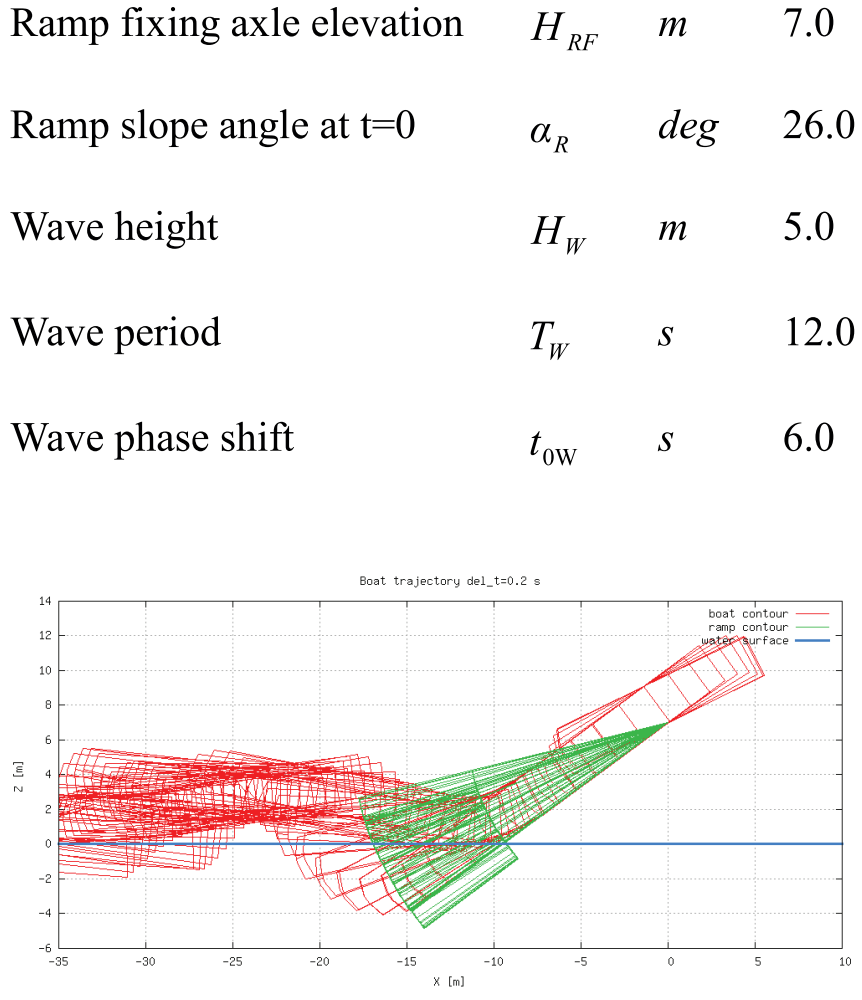

Fig. 6. Module and ramp contours in function of time, $\Delta \mathrm{t}=0.2 \mathrm{~s}$

The shift of starting point of launching in relation to wave propagation phase has a significant influence on motion dynamics of the rescue module, which may be clearly observed in Fig. $7 \mathrm{a}$, where for the time $\mathrm{t}=\sim 9 \mathrm{~s}$, a violent disturbance in runs of the curves of all three acceleration components, is visible. The disturbance results from the instantaneous contact between the ramp (with the module on it) and its support when the ramp reaches its maximum slope. The event, though noticeable, did not greatly influence the runs of velocity of the module. It's worth mentioning, that the run of contours of the going-off module is distinctly convex (Fig. 6). It results from that wave crest crosses module motion trajectory just in this moment.

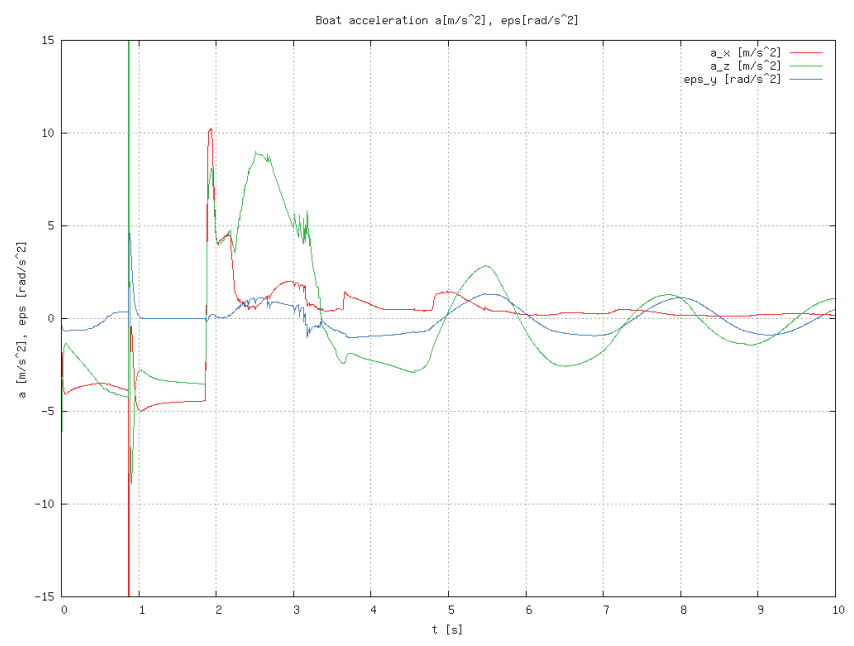

Fig. 7a. Module acceleration components: horizontal $\alpha_{x}$, vertical $\alpha_{z}$ and angular $\varepsilon_{z}$

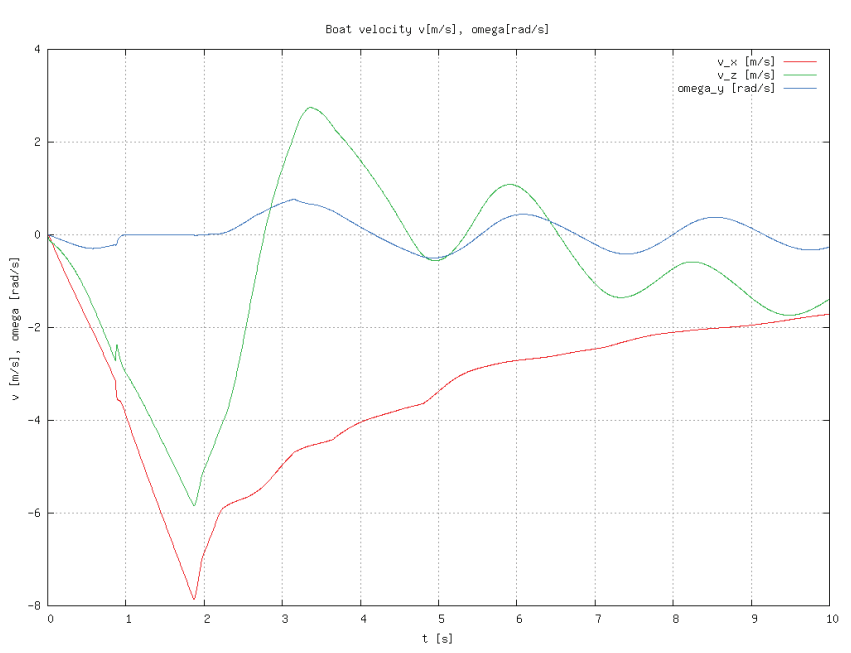

Fig. 7b. Module velocity components : horizontal $v_{x}$, vertical $v_{z}$ and angular $\omega_{\mathrm{y}}$

Scenario No. 4

In this case the calculations were conducted for calm sea and the same initial values of ramp position parameters, but for the ship alist. Results of the calculations have been intended to show influence of ship's heel on motion of the launching rescue module.

$\begin{array}{llll}\text { Ramp fixing axle elevation } & H_{R F} & m & 7.0 \\ \text { Ramp slope angle at t=0 } & & \mathrm{deg} & 26.0 \\ \text { Ship's heel angle } & \alpha_{R} & \mathrm{deg} & 15.0 \\ \text { Wave height } & H_{W} & m & 0.0 \\ \text { Wave period } & T_{W} & s & - \\ \text { Wave phase shift } & t_{0 \mathrm{~W}} & s & -\end{array}$

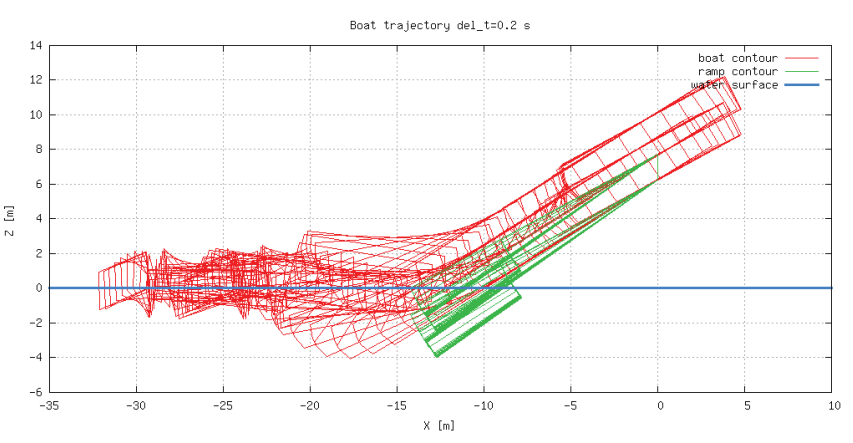

Fig. 8. Module and ramp contours in function of time, $\Delta \mathrm{t}=0.2 \mathrm{~s}$

As results from Fig. 8 , the runs of contours of the ramp and module in successive time intervals show that ship's heel greatly affects motion of the module, especially after its launching. It may be also observed that the distance covered by the module in the considered time interval is much shorter. It means that the motion of the module slows down due to increased module resistance to motion. The runs of accelerations and velocities 
shown in Fig. 9 confirm the conclusion. The instantaneous disturbances observed in acceleration runs reveal the instances when side surfaces of the module and the rollers fixed in the heeled ramp over which the module rolls down into, enter into contact to each other. It seems that this unit of the escape craft (launching system) and its mathematical model may be so elaborated as to obtain a more stable mode in which lateral loads can be transferred by the unit. As results from analysis of the velocity runs, duration time of moving the module along the ramp is longer, therefore the motion is slowed down.

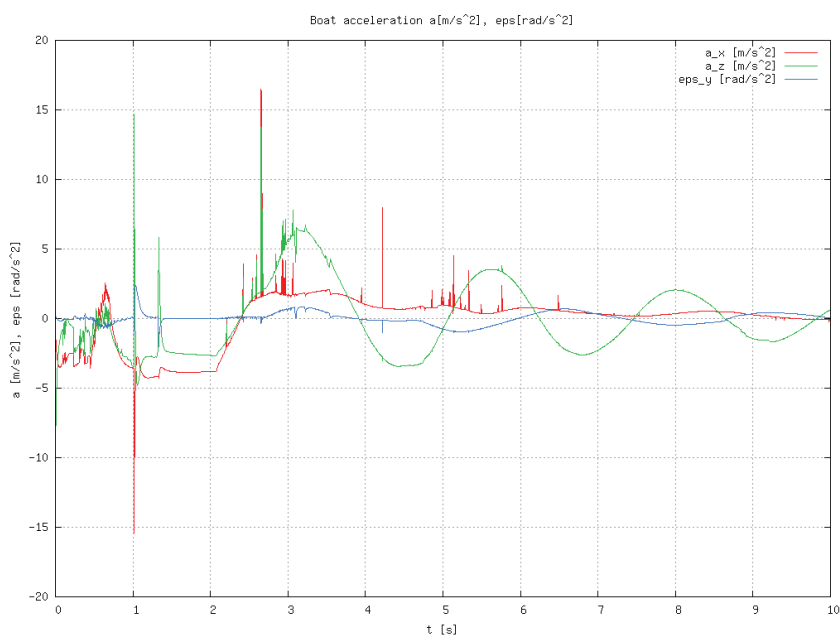

Fig. 9a. Module acceleration components: horizontal $\alpha_{x}$, vertical $\alpha_{z}$ and angular $\varepsilon_{\mathrm{z}}$

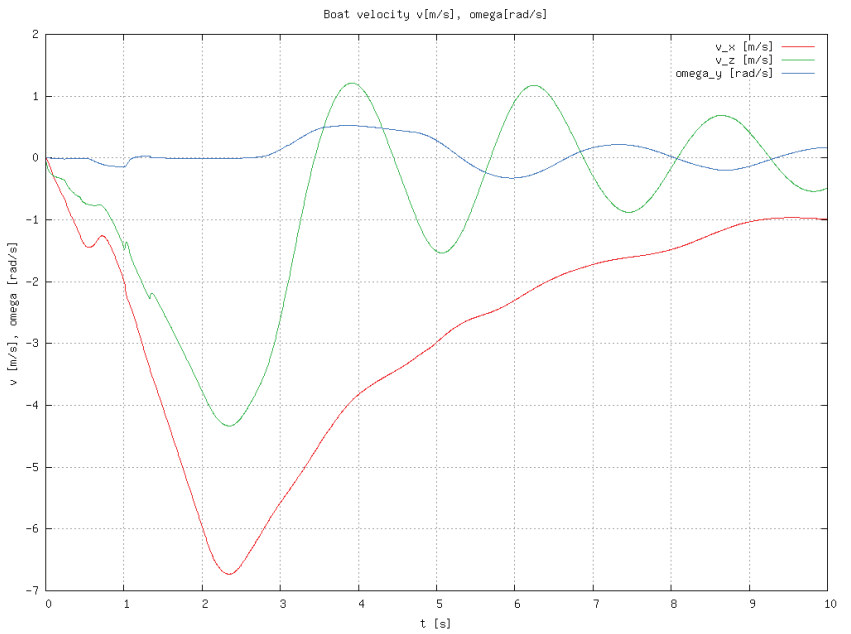

Fig. 9b. Module velocity components : horizontal $v_{\mathrm{x}}$, vertical $v_{\mathrm{z}}$ and angular $\omega_{\mathrm{y}}$

\section{ANIMATION OF MODULE LAUNCHING}

Fig. 10 and Fig. 11 show snapshots from animation of results of the computations conducted for scenario No. 1 and 6 .
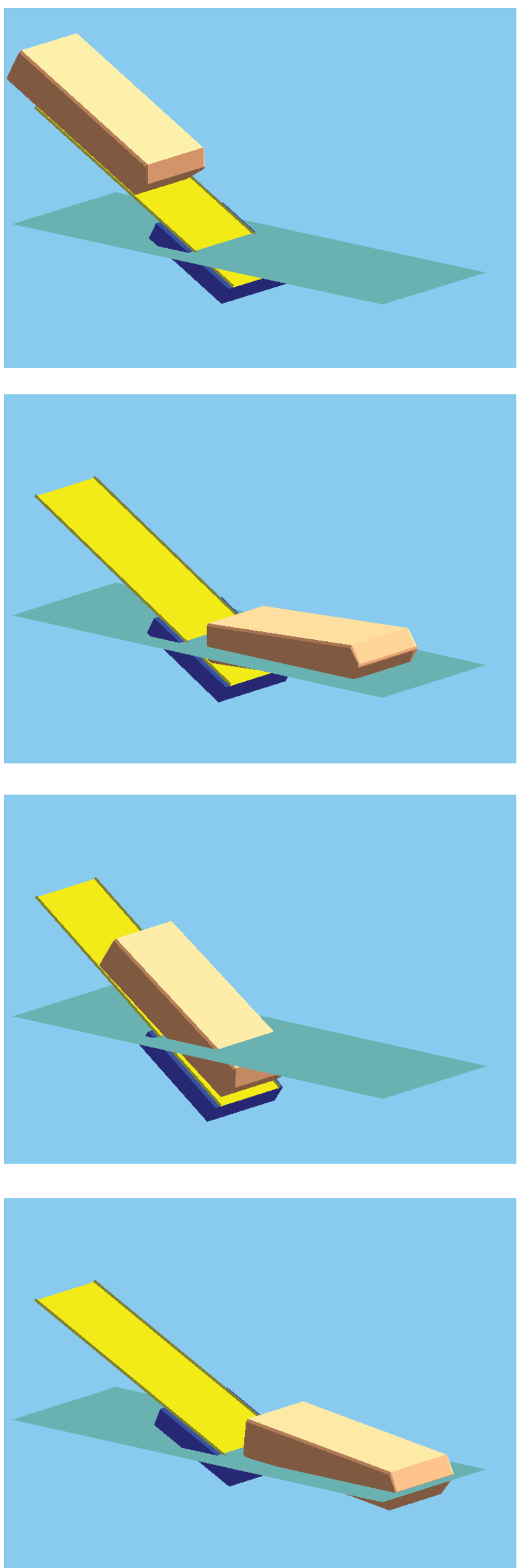

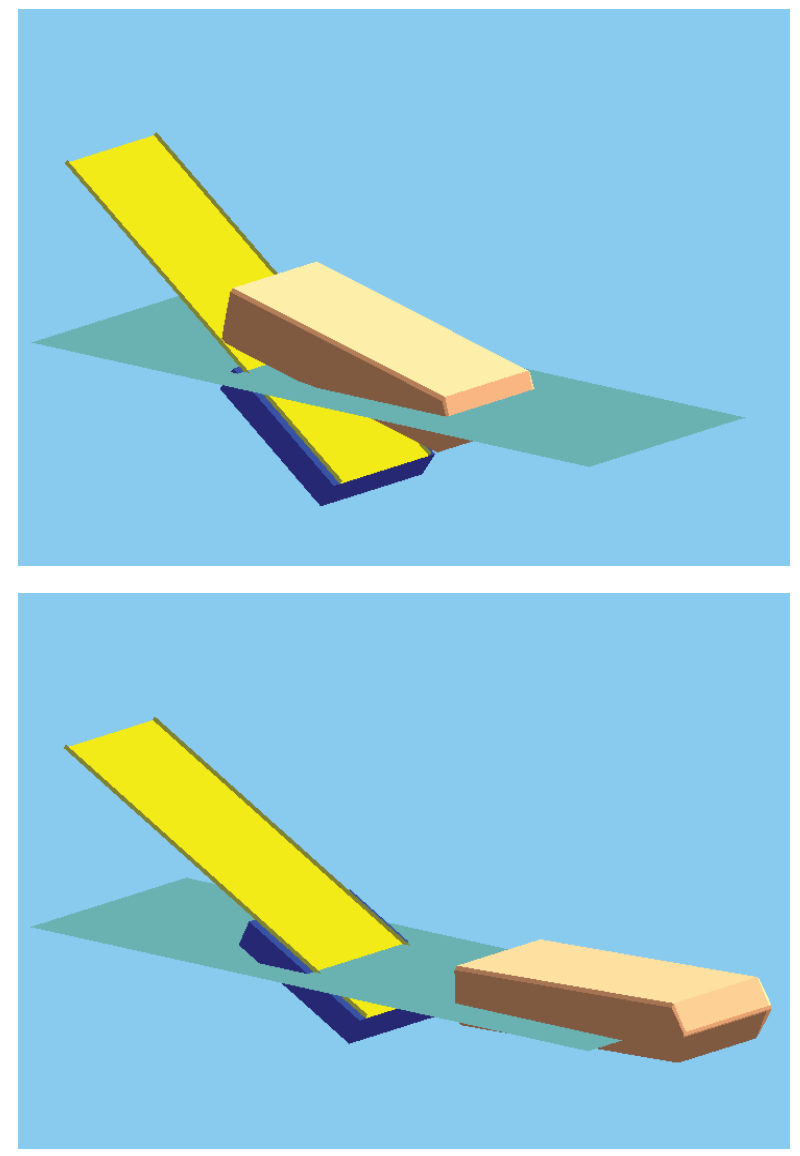

Fig. 10. Subsequent snapshots from simulation of rescue module launching into calm water, $\mathrm{H}_{\mathrm{RF}}=7 \mathrm{~m}, \mathrm{a}_{\mathrm{R}}=26$
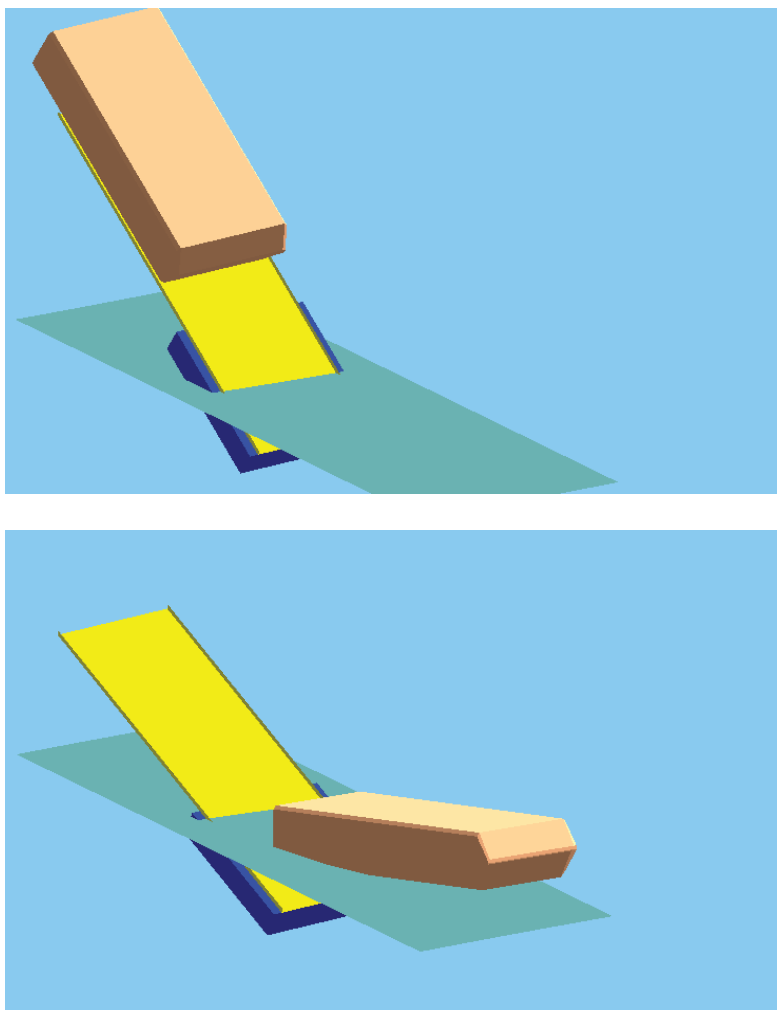
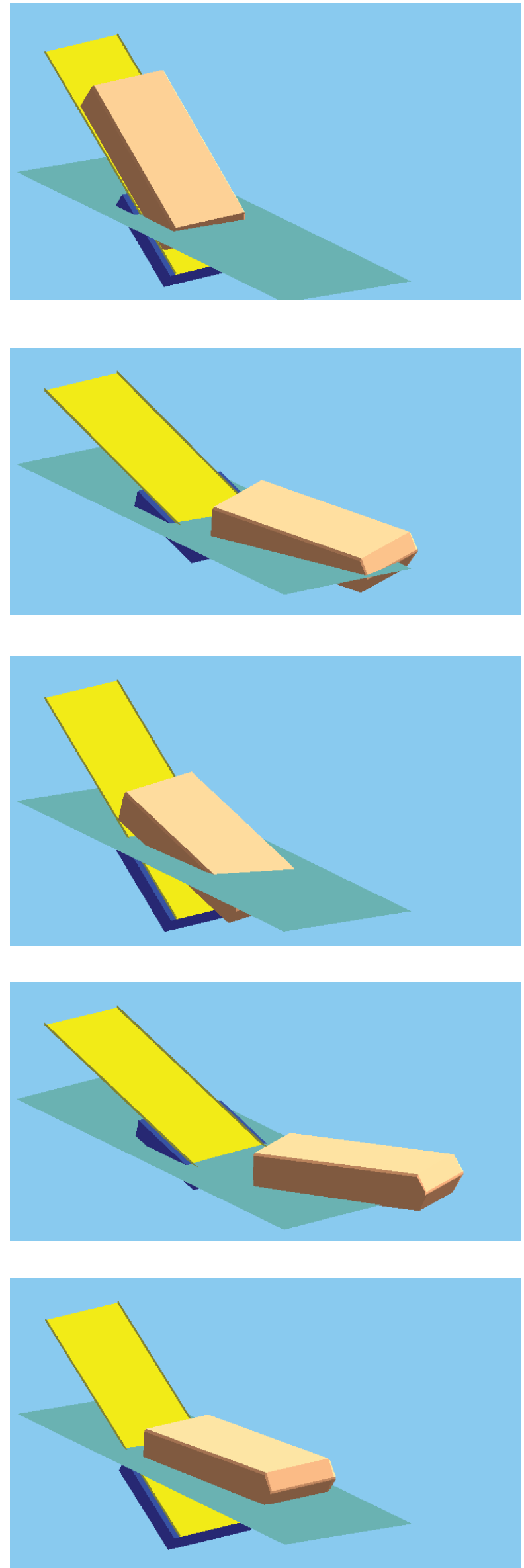


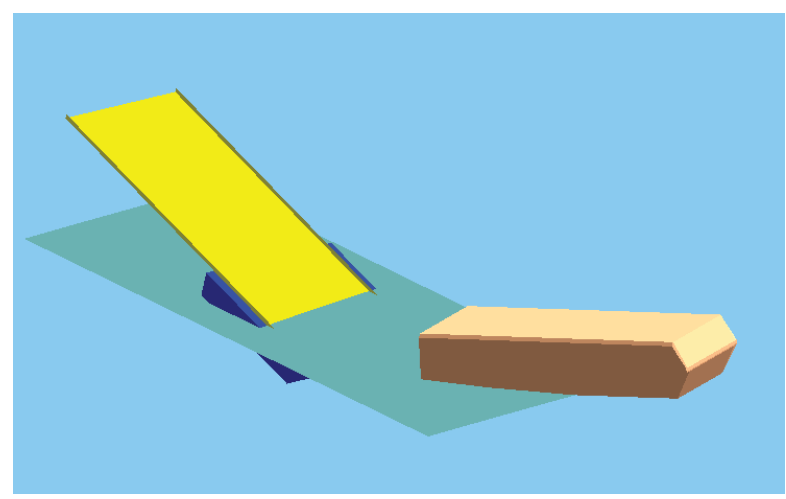

Fig. 11. Subsequent snapshots from simulation of rescue module launching into calm water, $\mathrm{H}_{\mathrm{RF}}=7 \mathrm{~m}, \mathrm{a}_{\mathrm{R}}=26^{\circ}$, ship heel angle $\theta=15^{\circ}$

\section{CONCLUSIONS}

The above presented results of computer simulations of performance of a rescue module during its launching dealt only with four selected scenarios, in view of a limited volume of this paper. The scenarios are relatively simple, but characteristic, and focused on correctness assessment of the developed method and computational software. However, it should be stressed that analysis of the presented runs enables to assess at least qualitatively the developed model. All the graphically presented results of calculations have been found in conformity with expectations and personal experience of these authors as far as the scientific field in question is concerned. Further research in this field is under way with hope of bringing results of simulations of escape craft motion in more complex and heavy weather conditions, with taking into account also ship motion in waves.

\section{BIBLIOGRAPHY}

1. 1. Dymarski P., Dymarski Cz.: „A numerical model to simulate the motion of a lifesaving module during its launching from the ship's stern ramp". Polish Maritime Research. Vol. 21, No 2 (82), 2014.

\section{CONTACT WITH THE AUTOR}

Czesław Dymarski, Prof. Paweł Dymarski, Ph. D.

\section{Gdańsk University of Technology Faculty of Ocean Engineering and Ship Technology \\ 11/12 G. Narutowicza Street 80-233 Gdańsk \\ Poland}

Telephone: +48583471608
+4858 3472397

Email: cpdymars@pg.gda.pl pawdymar@pg.gda.pl 